\title{
Keinginan Pindah Kerja (Turnover Intention) pada Tenaga Kesehatan di Rumah Sakit Umum SM Banyumas Propinsi Jawa Tengah
}

\author{
Panji Anggara*, Chriswardani Suryawati**, Farid Agushybana** \\ *RSU Siaga Medika Banyumas \\ ** Fakultas Kesehatan Masyarakat, Universitas Diponegoro \\ Email: Panjianggara.dr@gmail.com
}

\begin{abstract}
Based on the data in SM Banyumas Hospital in 2018, it was identified that in 2016, 2017 and 2018 there were employee turnover as much as 25,9\%, 22\% and $13 \%$. Eventhough it showed the decreasing rate in each year, but the turnover rate still considered high and could impact negatively for the hospital. This research aimed to analyze factors which cause turnover intention among health workers in SM Banyumas Hospital in Central Java. This was descriptive qualitative research with cross sectional approach. Researh subjects were health workers who already resigned from the hospital and health workers who still actively working in the hospital. Result of the research showed that leadership style, compensation, working partner, and career development are the organizational factors which affect turnover intention among health workers in SM Banyumas Hospital. While there were also external factors which also affect turnover intention. Most respondents stated that there were more interseting and beneficial job offer which caused them to turnover from the SM Banyumas Hospital.
\end{abstract}

Keywords: Turnover Intention, Human Resource, Hospital

\section{PENDAHULUAN}

Sumber daya manusia adalah orangorang dalam organisasi yang memberikan sumbangan pemikiran dan melakukan berbagai jenis pekerjaan dalam mencapai tujuan organisasi. Mengelola sumber daya manusia dalam organisasi rumah sakit tidak semudah mengelola sumberdaya lainnya seperti memindahkan barang atau alat kerja lainnya, karena manusia mempunyai harkat hidup, cipta, rasa dan karsa. ${ }^{1,2}$ Sementara dalam suatu organisasi rumah sakit berkumpul banyak orang dari berbagai jenis kompetensi, profesi, jenjang pendidikan, gender, dan motivasi sehingga masalahnya semakin komplek.

Salah satu masalah SDM yang sering dihadapi di suatu organisasi adalah terkait dengan turnover karyawan. Turnover intention adalah kecenderungan atau keinginan karyawan untuk berhenti bekerja atau berpindah keluar dari organisasi tempat saaat ini bekerja. Tingginya turnover intention juga menggambarkan penurunan motivasi kerja dan produktivitas karyawan. ${ }^{3}$ Tingkat turnover yang tinggi dapat menyebabkan kerugian bagi organisasi, karena itu perlu dilakukan upaya untuk mengurangi turnover intention pada pegawai. ${ }^{4}$

Berdasarkan data kepegawaian RSU SM Banyumas 2018, diperoleh informasi bahwa pada tahun 2016, 2017 dan 2018 dilaporkan angka turnover karyawan rumah sakit adalah $25,9 \%, 22 \%$ dan $13 \%$. Terdapat kecenderungan penurunan secara kuantitatif angka turnover menunjukkan bahwa upaya yang sudah dilakukan 
manajemen berhasil untuk menurunkan angka turnover. Namun tingkat turnover sebesar $13 \%$ dinilai masih tinggi dan merugikan rumah sakit. Ketika terjadi turnover khususnya tenaga Kesehatan di rumah sakit maka akan mengganggu pelayanan di rumah sakit, sistem kepegawaian rumah sakit, serta akan membebani rumah sakit dari segi biaya karena harus melakukan rekruitmen, seleksi hingga pelatihan dan orientasi kembali. ${ }^{5}$

Survei kepuasan terhadap tenaga kesehatan di rumah sakit umum SM Banyumas pada tahun 2018 memperoleh hasil kurang. Dari target kepuasan karyawan sebesar $80 \%$, diperoleh $50 \%$. Laporan dari bagian absensi masih didapatkan karyawan yang absensinya merah karena sering terlambat dan sering tidak masuk. Beberapa karyawan juga menunjukkan kinerja yang rendah. Penelitian ini bertujuan untuk menganalisis faktor-faktor yang menyebabkan keinginan pindah kerja (turnover intention) pada tenaga kesehatan di Rumah Sakit Umum SM Banyumas Provinsi Jawa Tengah.

\section{METODE PENELITIAN}

Jenis penelitian yang dikerjakan adalah penelitian deskriptif kualitatif. Pengumpulan data menggunakan metode cross sectional survey. Subyek dari penelitian atau informan adalah tenaga kesehatan di Rumah Sakit Umum SM Banyumas. Informan utama pertama adalah tenaga kesehatan yang telah resign dan sudah bekerja lebih dari 3 tahun sebanyak 11 orang. Informan utama kedua adalah tenaga kesehatan yang masih aktif bekerja tapi memiliki keinginan pindah dibuktikan dengan mengikuti seleksi CPNS dengam ,asa kerjanya 3 tahun atau lebih sejumlah 15 orang. Informan kunci adalah kepala ruang sejumlah 7 orang dan manajemen ada 4 orang terdiri dari staf kepegawaian, manajer sumber daya manusia, manajer keperawatan dan wakil direktur umum dan sumber daya manusia.

Penelitian dilakukan dengan wawancara mendalam pada informan dibantu dengan panduan wawancara. Validitas dalam penelitian ditekankan pada validitas tipologi atau klasifikasi. Agar data yang diperoleh valid diperhatikan ketepatan teknik pengumpulan data, kesesuaian informan, cara melakukan wawancara dan observasi dan cara membuat catatan lapangan. Langkah berikutnya teknik trianggulasi, dengan wawancara pada informan kunci dan diulang-ulang agar diperoleh data yang kuat dan valid.

Pengolahan dan analisis data dalam penelitian ini meliputi kodifikasi data, penyajian data dan penarikan kesimpulan dari temuan data. Interpretasi data pada penelitian menggunakan metode kualitatif dilakukan dengan strategi hermenetik dengan metode interpretasi penomenologis.

\section{HASIL DAN PEMBAHASAN}

Informan Utama pertama (IUa) yang diwawancarai terdiri dari 11 orang tenaga kesehatan yang sudah resign. IUa terdiri dari 6 orang laki-laki dan 5 orang perempuan. Usia antara 27 sampai 32 tahun dan masa kerja antara 3 sampai dengan 8 tahun. Pendidikan terakhir S1 kep Nurse 4 orang, S1 kes mas 1 orang, D3 kep 5 orang dan D3 analis lab 1 orang. Saat resign, 4 orang kepala ruang (Rekam Medis, Laboratorium, HD, CSSD), 1 orang perawat purna waktu di Komite PPI, 2 orang Perawat primer ICU,1 orang perawat primer di HD, 2 orang perawat asisten operasi, 1 orang perawat penata anestesi.

Informan utama kedua (IUb) yang diwawancarai terdiri dari 15 orang tenaga kesehatan yang masih bekerja. IUb terdiri dari 1 orang laki-laki dan 14 orang perempuan. Usia antara 25 sampai 34 tahun dan masa kerja antara 3 sampai dengan 9 tahun. Pendidikan terakhir dari informan semua D3. Saat dilakukan wawancara, 1 orang menjabat kepala ruang dan 7 orang PN dan 7 orang pelaksana.

\section{Budaya Organisasi}

Budaya organisasi adalah sistem yang dianut oleh anggota organisasi dan membedakan satu organisasi dengan 
organisasi yang lain. Budaya organisasi suatu organisasi mencerminkan bagaimana anggota organisasi tersebut berperilaku. ${ }^{6}$ Budaya organisasi merupakan pijakan bagi angota organisasi dan memiliki dampak terhadap turnover intention. Terdapat beberapa tipe budaya organisasi, dan penelitian sebelumnya di RS Prikasih menyatakan bahwa budaya organisasi berpengaruh secara signifikan terhadap turnover intention. ${ }^{7}$

\section{"Budaya organisasi ditempat kerja sudah bagus dengan menerapkan nilai- nilai Islam yang syar'i karena itu suatu bekal dalam kita merawat pasien agar tumbuh perasaan ikhlas dalam merawat pasien." IUa1}

"Budaya organisasi di tempat kerja saya menurut saya sangat baik karena mengacu pada pedoman nilai-nilai islami yang tinggi." IUb2

Nilai-nilai islam ini yang didoktrinkan oleh pemilik sebagai landasan pengelolaan rumah sakit. Penerapannya terlihat dalam cara berpakaian dan berpenampilan, bersikap dan berperilaku karyawan, cara berinteraksi baik dengan sesama karyawan, dengan manajemen maupun dengan pasien dan pengunjung. Budaya organisasi ini yang dibentuk dan dijadikan budaya kerja bagi seluruh karyawan rumah sakit supaya dapat mendorong terciptanya suasana nyaman baik bagi manajemen, karyawan, pasien maupun pengunjung.

Karyawan yang sudah keluar menyatakan bahwa saat mereka masih bekerja di Rumah Sakit Umum SM Banyumas, mereka merasa berada dalam lingkungan kerja yang nyaman dan kondusif. Budaya organisasi yang ada tidak menjadi sebab mereka keluar dari Rumah Sakit Umum SM Banyumas.

Budaya organisasi seharusnya dapat mendukung karyawan dalam melakukan pekerjaannya. Penelitian di Rumah Sakit Awal Bros Batam menyatakan bahwa budaya organisasi yang mendukung karyawan dalam bekerja misalnya terkait keterbukaan dalam penerapan kebijakan, dan budaya organisasi yang sesuai dengan tujuan organisasi mempengaruhi keinginan karyawan untuk turnover. Karyawan yang merasa bahwa budaya organisasi perusahaan sesuai dan mendukung pekerjaannya cenderung merasa puas dan tidak memiliki keinginan untuk berpindah. ${ }^{8}$

Penelitian sebelumnya pada perawat di rumah sakit di Jakarta juga menyatakan bahwa budaya organisasi merupakan alat manajemen yang harus dikelola dengan baik untuk menciptakan lingkungan kerja yang kondusif dan produktif. Budaya organisasi merupakan salah satu alasan para perawat untuk tetap bertahan di rumah sakit tersebut. ${ }^{3}$

\section{Gaya Kepemimpinan}

Gaya kepemimpinan berkaitan erat dengan kinerja serta kepuasan kerja karyawan di suatu organisasi. Menerapkan gaya kepemimpinan yang sesuai di dalam organisasi merupakan salah satu cara untuk meningkatkan kinerja dan kepuasan kerja karyawan. Pemimpin harus mengetahui karakteristik pegawai serta budaya organisasi agar dapat menerapkan gaya kepemimpinan yang sesuai. Pemimpin yang baik tidak hanya mampu mengarahkan anggotanya, namun juga dapat memberikan motivasi, menjadi teladan, serta berupaya mencapai prestasi kerja yang unggul. ${ }^{9}$

"Selain itu kurangnya perhatian manajemen dalam menghargai jasa maupun loyalitas karyawan yang telah lebih lama bekerja menimbulkan titik jenuh dan berkurangnya semangat karyawan yang telah setia bekerja untuk RS dalam mengemban amanah untuk mengembangkan Perusahaan/ RS..." IUb 3

"Tidak jelasnya reward dan punishment dari atasan menimbulkan lingkungan kerja negatif. tidak ada staf yg berusaha meningkatkan 
kapasitasnya, cenderung pasif, datang kerja hanya menunggu waktu pulang, dan secara umum menunggu waktu selesai kontrak untuk mencari tempat yang lain.Atasan mudah memberhentikan dan mudah mencari pengganti, membuat staf merasa tidak ada yg posisinya aman di rumah sakit, maka ketika habis kontrak langsung memilih keluar dari pada perpanjang kontrak." IKa4

Informan menyatakan bahwa gaya kepemimpinan atasan adalah salah satu alasan mereka merasa tidak nyaman dan tidak puas sehingga memutuskan untuk keluar. Pimpinan dirasa kurang memberikan perhatian kepada karyawan. Selain itu pimpinan juga kurang mampu memberikan arahan yang tegas sehingga karyawan tidak merasa termotivasi untuk bekerja. Kepercayaan kepada pimpinan yang rendah merupakan salah satu penyebab karyawan memiliki keinginan untuk berpindah.

Gaya kepemimpinan mempengaruhi kenyamanan karyawan dalam bekerja. Beberapa penelitian lain menyatakan bahwa gaya kepemimpinan yang buruk adalah salah satu alasan pegawai berpindah pekerjaan. Pimpinan yang dapat memotivasi karyawan dibutuhkan agar karyawan dapat lebih optimal dalam menjalankan pekerjaannya dan merasa puas dalam bekerja. ${ }^{4,8}$

Penelitian di RSU Premagana juga menyatakan bahwa menjaga hubungan yang baik antara bawahan dan atasan merupakan salah satu upaya yang dapat dilakukan untuk mengurangi turnover intention..$^{10}$ Penelitian lain di RS Awal Bros Batam juga menguatkan pentingnya kepemimpinan terhadap tunrover intention. Penelitian tersebut menyatakan bahwa hubungan yang kurang baik antara bawahan dan atasa langsung, pimpinan yang terlalu reaktif terhadap kesalahan, bersikap subyektif dan membuat komunikasi menjadi terbatas merupakah salah satu alasan utama dari turnover karyawan. ${ }^{11}$

\section{Kompensasi}

Hasil wawancara dengan Informan yang sudah keluar diperoleh informasi pemberian kompensasi di Rumah Sakit Umum SM Banyumas kurang memperhatikan tingkat pendidikan, masa kerja dan kemampuan karyawan. Pemberian kompensasi dinilai belum mempertimbangkan pendidikan, masa kerja, dan kemampuan karyawan tetapi hanya memenuhi standar aturan pemerintah mengenai upah minimum regional. Karyawan dengan pendidikan sarjana atau nurse, diberikan kompensasi yang sama dengan karyawan yang berpendidikan diploma 3. Antara karyawan baru dengan karyawan yang sudah bekerja lebih dari 3 tahun, tidak ada perbedaan signifikan terkait kompensasi bahkan cenderung setara. Sementara dalam pelayanan, karyawan lama harus membimbing dan melatih karyawan baru yang kemampuan, keterampilan dan pengalamannya masih kurang.

"Karyawan yang memilih
mengundurkan diri lebih dominan
karena alasan aturan kompensasi yang
tidak adil." IKb1

"Skema penggajian tidak ada perbedaan yang signifikan antara karyawan lama dan baru. Nominal gaji yang di dapat tidak sebanding dengan beban kerja." IKa4

"Penggajian sudah dibayarkan sesuai UMR, tetapi secara terstruktur sesuai pendidikan, profesi dan tahun masuk memang masih belum disesuaikan. Insyaallah sedang dibahas pemberlakuannya secara bertahap."

\section{IKa3}

Kompensasi sangat berkaitan dengan kepuasan kerja karyawan. Karyawan yang merasa bahwa kompensasi yang mereka dapatkan belum sesuai dengan kinerja yang dilakukan akan merasa tidak puas dan 
cenderung memiliki keinginan untuk berpindah. ${ }^{12,13}$ Pemberian kompensasi yang layak adalah salah satu cara untuk mencegah terjadinya turnover. Penelitian di RS Umum Premagana juga menyatakan bahwa kepuasan karyawan terhadap kompensasi atau gaji berpengaruh signifikan terhadap turnover intention. Semakin tinggi kepuasan karyawan terkait gaji, maka semakin rendah turnover intention karyawan. ${ }^{10}$

Kompensasi tidak hanya berupa kompensasi finansial berupa gaji, namun juga terkait non-finansial seperti kenyamanan tempat kerja, jaminan kesehatan, bonus, dan lain sebagainya. ${ }^{9}$ Pemberian kompensasi yang dinilai tidak adil juga dapat menimbulkan konflik antar rekan kerja dan menyebabkan karyawan merasa kurang dihargai kinerjanya sehingga berdampak negatif pada kinerja karyawan. ${ }^{14}$

\section{Rekan Kerja}

Kenyamanan dalam bekerja bersama dengan rekan kerja dapat meningkatkan kepuasan kerja dan kinerja seorang karyawan. Karyawan yang merasa nyaman dan menikmati bekerja bersama rekan kerjanya cenderung lebih termotivasi untuk menyelesaikan pekerjaan dengan baik sesuai target kinerja. ${ }^{15}$

\section{"Rekan-rekan di tempat kerja kerjasamanya baik sesuai dengan tanggungjawabnya masing-masing, saling terbuka, musyawarah, saling legowo saat menerima masukan demi kebaikan kami semua dan tidak ada yang saling menjatuhkan. Kami semua adalah keluarga." IUa2}

\footnotetext{
Rekan kerja memiliki dampak langsung terhadap kepuasan kerja karyawan. Penelitian di RS PHC Surabaya menyatakan bahwa rekan kerja yang mendukung dan kooperatif berpengaruh secara signifikan terhadap kepuasan kerja sehingga mengurangi keinginan karyawan untuk berpindah pekerjaan. ${ }^{16}$ Lingkungan
}

kerja yang baik akan mendorong sesama rekan kerja untuk saling mendukung untuk menyelesaikan pekerjaan yang dibebankan kepada mereka. ${ }^{17}$

Berpindahnya karyawan di suatu organisasi juga akan mempengaruhi kinerja rekan kerja karyawan tersebut. Ketika karyawan merasa bahwa rekan kerja yang mendukung pekerjaannya berpindah, maka akan timbul potensi gangguan terhadap pola sosial yang sudah berjalan selama ini di unit kerja. Hal ini merupakan salah satu konsekuensi negatif dari turnover karyawan. ${ }^{4}$

Penelitian lain di RS Pura Raharja juga menyatakan bahwa kepuasan karyawan terhadap rekan kerja merupakan faktor penting yang mempengaruhi kepuasan kerja dan keinginan untuk berpindah. Beberapa karyawan yang sudah lama bekerja di RS Pura Raharja juga menyatakan bahwa alasan bertahan di rumah sakit tersebut adalah karena sudah merasa nyaman dengan rekan kerja dan fasilitas lain yang diberikan oleh rumah sakit. ${ }^{18}$

\section{Pengembangan Karir}

Pengembangan karir adalah salah satu faktor internal yang dapat mempengaruhi kepuasan kerja dan keinginan untuk berpindah kerja. Pengembangan karir terkait kesempatan untuk promosi, merencanakan jenjang karir, dan pengembangan kompetensi diri. ${ }^{4}$

"Jenjang karir dan jenjang karyawan yang tidak jelas. Hal ini menyebabkan karyawan merasa tidak mungkin berkembang bersama RS, meskipun RS terus berkembang. juga berdampak pada perencanaan pengembangan karyawan. tidak ada perencanaan pengembangan karyawan yang terorganisir, sehingga banyak staf yang akhirnya kesulitan memenuhi kredit poin organisasi profesi." IKa4

Pengembangan karir atau jenjang karir tidak hanya terkait dengan 
kompensasi, namun juga keinginan karyawan untuk berkembang dan meningkatkan kompetensinya. Penelitian sebelumnya di RS Bedah Surabaya menyatakan bahwa sebagian besar pegawai rumah sakit memiliki keinginan yang tinggi untuk mengembangkan karirnya. Pengembangan karir yang dimaksud terkait dengan peningkatan keahlian, proses pengembangan diri, dan pencapaian tujuan yang diharapkan terkait karir pada setiap individu. ${ }^{14,16}$

Pengembangan karir juga termasuk adanya kesempatan untuk mendapatkan promosi jabatan di organisasi. Penelitian di RS Pancaran Kasih GMIM Manado menyatakan bahwa promosi jabatan berpengaruh secara signifikan terhadap turnover intention. Kesempatan untuk mendapatkan promosi jabatan perlu disampaikan secara terbuka kepada karyawan, sehingga dapat memahami dan merencanakan target kinerja apa yang harus dicapai agar mendapatkan kesempatan promosi. ${ }^{19}$

\section{Tawaran Kerja di Tempat Lain}

Faktor eksternal juga mempengaruhi keinginan karyawan untuk berpindah kerja, salah satunya adalah adanya tawaran pekerjaan di tempat lain yang dinilai lebih baik daripada pekerjaan saat ini.

"Kalau alasan pindah, karena saya masih punya kesempatan menjadi ASN. Saya rasa memang banyak orang yang ingin menjadi ASN." IUa6

"Kenapa saya mencoba mendaftar CPNS karena dari sisi kompensasi lebih menjanjikan. Ada tunjangan, ada gaji ke 13 dll. kalau masih ada kesempatan kenapa tidak." IUb 14

Informan menyatakan bahwa adanya kesempatan untuk mengikuti seleksi adalah salah satu alasan untuk berpindah. Hal ini karena jaminan kompensasi serta pengembangan karir atau jenjang karir bagi ASN dinilai lebih menguntungkan dibandingkan di Rumah Sakit SM Banyumas. Penelitian sebelumnya menyatakan bahwa keinginan karyawan untuk mendaftar sebagai ASN merupakan alasan tertinggi kedua untuk turnover. ${ }^{5}$ Keinginan bekerja menjadi ASN ini disebabkan karena job security sebagai ASN dinilai lebih baik dan juga budaya di Indonesia yang menilai bahwa menjadi ASN adalah suatu kebanggaan. ${ }^{20}$

\section{KESIMPULAN}

Hasil penelitian dapat disimpulkan bahwa gaya kepemimpinan, kompensasi, kepuasan kerja, dan pengembangan karir adalah faktor organisasi yang menyebabkan tenaga Kesehatan di Rumah Sakit Umum SM Banyumas memiliki keinginan untuk berpindah kerja. Selain itu faktor eksternal seperti penawaran yang menarik dari institusi lain serta institusi lain yang menjanjikan kesejahteraan yang lebih baik juga turut menjadi alasan bagi tenaga Kesehatan di Rumah Sakit SM Banyumas untuk berpindah.

\section{UCAPAN TERIMA KASIH}

Peneliti mengucapkan terima kasih kepada Direksi RSU SM Banyumas serta seluruh informan yang telah bersedia berpartisipasi dalam penelitian ini.

\section{DAFTAR PUSTAKA}

1. Hasibuan MSP. Manajemen Sumber Daya Manusia. Ed Revisi Jakarta Bumi Aksara. Epub ahead of print 2011.

DOI: 10.1017/CBO9781107415324.004.

2. Widajat R. Being A Great and Sustainable Hospital. Jakarta: PT. Gramedia Pustaka Utama, 2009.

3. Sinaga SV, Tarigan E, Bandur A. The Mixed-Methods Study of Nursing Perception on Organizational Culture and Turnover in Hospital. Indones J Heal Res 2019; 2: 49-59.

4. Mujiati NW, Dewi AASK. FaktorFaktor Yang Menentukan Intensi Turnover Karyawan Dalam 
Orgaisasi. J Ilm Forum Manaj 2016; 14: 56-63.

5. Dewanto A, Wardhani V. Nurse turnover and perceived causes and consequences: A preliminary study at private hospitals in Indonesia. BMC Nurs; 17. Epub ahead of print 2018. DOI: 10.1186/s12912-0180317-8.

6. Robbins SP, Judge TA. Organizational Behavior 15th Edition. prentice Hall, 2012.

7. Rahmawati E. Analisis Hubungan Budaya Organisasi, Komitmen Organisasi dengan Turnover Intention Perawat Rumah Sakit Prikasih Tahun 2015. J Adm Rumah Sakit Indones 2016; 2: 204-213.

8. Sulastri E, Arif Y, Wardhani UC. Hubungan Budaya Organisasi dengan Intensi Turnover di Rumah Sakit Awal Bros Batam. J Endur 2019; 4: 464-469.

9. Asmara AP. Pengaruh Turnover Intention terhadap Kinerja Karyawan di Rumah Sakit Bedah Surabaya. $J$ Adm Kesehat Indones 2018; 5: 123129.

10. Putra DGEK, Surya IBK. Pengaruh Kepuasan Gaji Terhadap Turnover Intention Dengan Komitmen Organisasional Sebagai Mediasi pada Rumah Sakit Umum Primagana. E-Jurnal Manaj Univ Udayana 2016; 5: 4281-4308.

11. Christiani L, Ilyas J. Analisis Faktor yang Berhubungan dengan Turnover Perawat di Rumah Sakit Awal Bros Batam Tahun 2017. J Adm Rumah Sakit Indones 2020; 4: 198-209.

12. Pawesti R, Wikansari R. PENGARUH KEPUASAN KERJA TERHADAP INTENSI TURNOVER KARYAWAN DI INDONESIA. J Ecopsy 2016; 3: 4967.

13. Widayati C, Yunia Y. PENGARUH KOMPENSASI DAN BUDAYA ORGANISASI TERHADAP TURNOVER INTENTION. J Manaj
2016; XX: 387-401.

14. Santi MW, Nandini N, Alfiansyah G. THE EFFECT OF BURNOUT SYNDROME ON TURNOVER INTENTION USING ORGANIZATIONAL COMMITMENT AS AN INTERMEDIATE VARIABLE. $J$ Adm Kesehat Indones 2020; 8: 109_ 122.

15. Rachman L, Dewanto A. Pengaruh Employee Engagement terhadap Kepuasan Kerja dan Turnover Intention Perawat (Studi pada Rumah Sakit Wava Husada Kepanjen Malang). J Apl Manaj 2016; 14: 322-333.

16. Nandini N, Nurul T, Fakultas R, et al. PENYEBAB TURNOVER INTENTION PADA PEGAWAI INSTALASI GIZI RUMAH SAKIT PHC SURABAYA EMPLOYEE TURNOVER INTENTION CAUSES IN NUTRITION DIVISION OF PHC SURABAYA HOSPITAL. J Adm Kesehat Indones Vol 1 Nomor 3 Juli-Agustus 2013 2013; 1: 272-279.

17. Sakul A. Pengaruh Kepuasan Kerja, Beban Kerja Dan Komitmen Organisasi Terhadap Turnover Intention Perawat RS. Bhayangkara TK. III Manado. J Ris Bisnis dan Manaj 2018; 6: 175-184.

18. Putra MFR. Pengaruh Kepuasan Kerja dan Komitmen Organisasi Terhadap Intention to Leave di Rumah Sakit Pura Raharja Surabaya. J Adm Kesehat Indones 2017; 5: 99104.

19. Siwi G, Taroreh R, Dotulong L. PENGARUH KEPUASAN GAJI, PROMOSI JABATA, KOMITMEN ORGANISASI TERHADAP TURNOVER INTENTION KARYAWAN RSU GMIM PANCARAN KASIH MANADO. $J$ EMBA J Ris Ekon Manajemen, Bisnis dan Akunt 2016; 4: 932-951.

20. Indrawan D. Path Analysis (Analisis 
Jalur) : Pengaruh quality work life terhadap employee engagement dan turnover intention perawat Rumah Sakit. J Islam Med 2020; 4: 52-64. 